\title{
$10 \mathrm{MW}$ 급 초전도 풍력발전기 계자코일 전자장 해석
}

\author{
Magnetic Field Analysis of the Field Coil for 10 MW Class \\ Superconducting Wind Turbines
}

\author{
김지형 ${ }^{1}$, 박사일 ${ }^{1}$, 김호민 ${ }^{2, *}$ \\ Ji-Hyung Kim ${ }^{1}$, Sa-Il Park ${ }^{1}$, Ho-Min Kim ${ }^{2, *}$
}

\begin{abstract}
This paper presents the magnetic field analysis of the racetrack double pancake field coil for the 10 MW class superconducting wind turbine which is considered to be the next generation of wind turbines using the 3 Dimensional FEM(Finite Elements Method). Generally, the racetrack-shaped field coil which is wound by the second generation $(2 \mathrm{G})$ superconducting wire in the longer axial direction is used, because the racetrack-shaped field coil generates the higher magnetic field density at the minimum size and reduces the synchronous reactance. To analysis the performance of the wind turbines, It is important to calculate the distribution of magnetic flux density at the straight parts and both end sections of the racetrack-shaped high temperature superconductivity(HTS) field coil. In addition, Lorentz force acting on the superconducting wire is calculated by the analysis of the magnetic field and it is important that through this way Lorentz force can be used as a parameter in the mechanical analysis which analyzes the mechanical stress on the racetrack-shaped field coil.
\end{abstract}

Key words : 2G superconducting wire, 3D FEM, Lorentz force, magnetic field distribution, racetrack-shaped field coil.

\section{1.서 론}

현재 화석연료의 고갈로 인한 지속적인 유가상승과 지구 온난화 현상으로 인한 대체 에너지에 대한 연구 와 개발이 활발히 진행 중이며 국내에서도 세계적인 추세에 발맞춰 신재생에너지 기술 개발에 집중하고 있 으며 이산화탄소발생억제를 위해 신재생에너지 의무할 당제 (RPS)를 시행하고 있다. 이러한 신재생에너지원

\footnotetext{
1 학생회원 : 제주대 대학원 전기공학과 석사과정

1 학생회원 : 제주대 대학원 풍력특성화협동과정 석사과정

2정 회 원 : 제주대 공대 전기공학과 조교수

*교신저자 : hmkim@jejunu.ac.kr

원고접수 : 2012년 07월 19일

심사완료 : 2012년 09월 17일

게재확정 : 2012년 09월 17일
}

중 풍력발전은 단위 면적당 수급 가능한 에너지가 타 신재생 에너지원들 보다 높으므로 현재 가장 각광받고 있는 에너지원으로 볼 수 있다.

현재까지 풍력발전기는 대부분 육상에 설치되어 운 전되고 있지만 $5 \mathrm{MW}$ 급 이상의 대형풍력발전기가 개 발되면서 풍력발전은 해상화 및 대용량화 되어가는 추 세이다. 하지만 $6 \mathrm{MW}$ 급 이상에서는 발전기 무게 증 가로 인한 기술적 한계를 보임에 따라 초전도 풍력발 전기가 주요 대안 중 한가지로 떠오르고 있다. 초전도 발전기는 기존 직접구동형 영구자석형 동기발전기 대 비 약 무게는 $33 \%$ 로 가벼워지고 크기가 $40 \%$ 가 줄어 든다. 그리고 기기손실은 최대 $60 \%$ 가량 줄일 수 있 다. 이에 따라 $5 \mathrm{MW}$ 급 이상에서 경제성이 상대적으 로 우수해진다[1-2].

현재 전 세계적으로 초전도 발전기 개발 동향을 살 펴보면, 유럽에서는 영국 Converteam사가 $8 \mathrm{MW}$ 급 고온초전도 풍력발전기 개발을 진행 중이며, 미국에서 는 $\mathrm{GE}$ 와 $\mathrm{AMSC}$ 사가 $10 \mathrm{MW}$ 이상급 고온초전도 풍 력발전기 개발을 진행 중에 있다. 국내에서도 미래의 해상풍력 시장의 주도권을 선점하기 위한 $10 \mathrm{MW}$ 급 고온초전도 풍력발전기 설계의 핵심 원천기술을 개발 하기 위해 노력 중에 있다[2]

초전도 풍력발전기의 회전자는 $2 \sim 5 \mathrm{~T}$ 크기의 자계 를 만들어냄과 동시에 풍력발전기 운전 특성상 풍속 및 풍향이 실시간으로 변하기 때문에 회전자 내부의 초전도계자코일이 받는 전자기적 응력은 매우 커지게 된다. 따라서 초전도계자코일의 자장분포해석과 이를 바탕으로 한 Lorentz force 산출을 통해 $2^{\text {nd }}$ Generation(2G) 고온초전도체 (HTS)를 이용한 초전 도계자코일의 신뢰성 확보 기술이 선행되어야 한다.

본 논문에서는 $2 \mathrm{D}, 3 \mathrm{D} \mathrm{FEM}$ 을 이용하여 Doublepancake(DP) Racetrack형 초전도 계자코일의 정자 장해석을 수행하였으며 이를 통해 수평자장 $(\mathrm{B} / /)$ 에 따른 Lorentz force 산출 및 수직자장 $(\mathrm{B} \perp)$ 에 따른 임계전류 (Ic) 값을 산출하였다.

\section{2. 본 론}

2.1. $10 \mathrm{MW}$ 급 초전도 발전기 개념설계와 초전도 계자코일 2차원 정자장 분포 해석

표 1은 본 논문에서 해석하고자 하는 $10 \mathrm{MW}$ 급 초 전도 풍력발전기의 사양 표이며 그림 1 은 그에 따른 개념 설계 안 이다. $10 \mathrm{rpm}$ 의 동기속도로 회전하는 동기발전기 이므로 고온초전도 계자코일은 총 6 극으로 한극 당 4 개의 DP Racetrack 코일과 1 개의 Single - pancake(SP) Racetrack 코일이 적층되어 있는 구 조를 갖는다. 고정자는 철심을 제거한 공심형으로 총 
Table 1. Specifications of the $10 \mathrm{MW}$ class S uperconducting Wind Turbines.

\begin{tabular}{|c|c|}
\hline 사양 & 설계치 \\
\hline 정격 용량 & $10[\mathrm{MW}]$ \\
\hline 주파수 & $0.5 〔 \mathrm{~Hz}]$ \\
\hline 극수 & 6 \\
\hline 회전수 & $10[\mathrm{rpm}]$ \\
\hline 단자 전압 & $6600[\mathrm{~V}]$ \\
\hline 역기전력 & $6719[\mathrm{~V}]$ \\
\hline 역률 & 1.0 \\
\hline 동기리액턴스 & $0.2\lceil p . u]$ \\
\hline 계자 정격 전류 & $360[\mathrm{~A}]$ \\
\hline 계자 턴 수 & 45474 \\
\hline 직선부 최대 발생 자장 & $9.67[\mathrm{~T}]$ \\
\hline 고온 초전도 (HTS) 선재 량 & $213.3[\mathrm{~km}]$ \\
\hline 계자 도체 정격 전류 밀도 & $167\left[\mathrm{~A} / \mathrm{mm}^{2}\right]$ \\
\hline 고정자 슬롯 수 & 108 \\
\hline 고정자 코일 상당 턴 수 & 360 \\
\hline 고정자 외경 & $3.647 \mathrm{~m}$ \\
\hline 고정자 도체 정격 전류 밀도 & $\begin{array}{c}6.2\left[\mathrm{~A} / \mathrm{mm}^{2}\right] \\
\text { (강제수냉식) }\end{array}$ \\
\hline 계자 코일 축 방향 직선 부 길이 & $1574[\mathrm{~mm}]$ \\
\hline
\end{tabular}
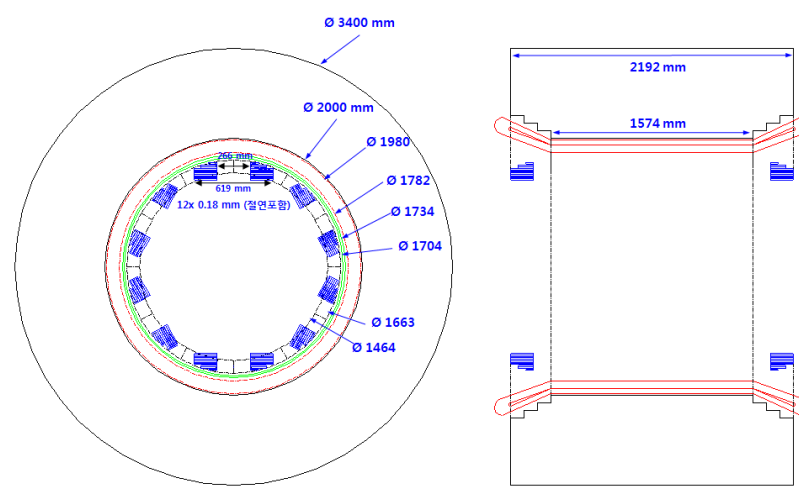

Fig. 1. Cross- ${ }^{-}$sectional diagram of the $10 \mathrm{MW}$ class Superconducting Wind Turbines.

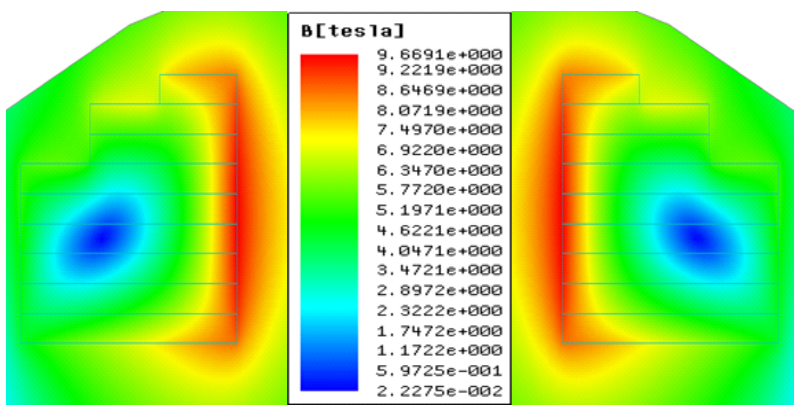

Fig. 2. 2D magnetic flux density distribution of Racetrack type DP Field coil.

슬롯 수는 108 개이며 구리도선이 이층, 전절권으로 권선되어 있다. 계자 코일에 $360 \mathrm{~A}$ 의 정격전류가 흘 렀을 경우의 자장 분포를 해석하였다.

그림 2 는 초전도 계자코일의 2 차원 구조와 자장분 포이다. 2차원 자장분포 해석결과 초전도 발전기의 성 능을 결정하는 $\mathrm{DP}$ 계자코일 직선 부 최대발생자장은 $9.67 \mathrm{~T}$ 이며 직선 부 안쪽에서 발생한다.

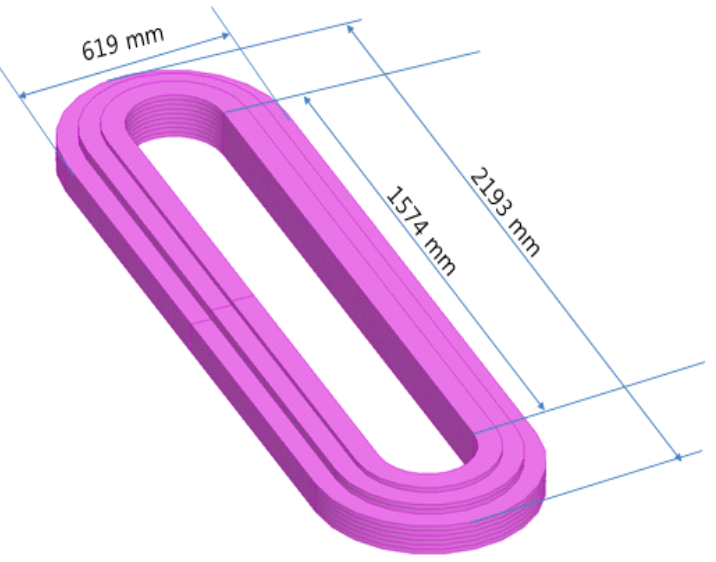

Fig. 3. Structure of the double-pancake racetrack coil.

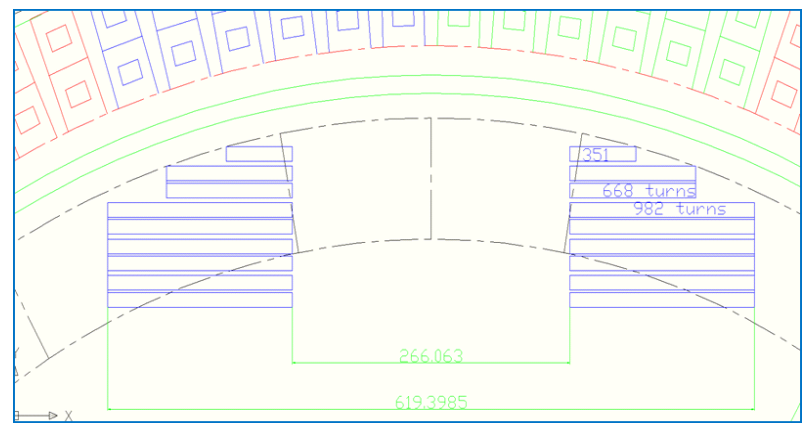

Fig. 4. Cross-sectional view of the HTS field coil for 1 pole.

\subsection{Racetrack형 계자코일 3차원 정자장 분포해석}

그림 3은 고온초전도 Racetrack형 계자 코일의 3 차원 구조이다. 계자 코일의 외경은 $619 \mathrm{~mm}$ 이고 계 자코일 축방향 직선 부 길이는 $1574 \mathrm{~mm}$ 이며 $\mathrm{A}$ 사의 12 (폭) $\times 0.18 \mathrm{~mm}$ (두께)의 $2 \mathrm{G} \mathrm{YBCO}$ 초전도 선재 가 사용되었다. 본 논문의 해석을 위해 사용된 $\mathrm{A}$ 사의 $2 \mathrm{G}$ 선재는 폭 $4 \mathrm{~mm}$ 일 경우 냉각온도 $77 \mathrm{~K}$, 자기자 장 하에서 $130 \mathrm{~A}$ 의 임계전류 값을 갖는다. 이에 따라 $12 \mathrm{~mm}$ (폭)선재를 기준으로 환산하면 임계전류 크기 는 $390 \mathrm{~A}$ 가 되며 $30 \mathrm{~K}$ 까지 운전온도를 냉각할 경우 최대 임계전류가 $2340 \mathrm{~A}$ 까지 커지게 된다. 코일의 총 권선 수는 351 턴, 2,3 층 $\mathrm{SP}$ 코일은 668 턴이며 그 외의 $\mathrm{SP}$ 코일은 982 턴이다. 이에 따른 $\mathrm{HTS}$ 선재 총사용량은 $213.3 \mathrm{~km}$ 이다.

고정자와 회전자 사이의 공극이 $1 \mathrm{~mm}$ 정도밖에 되지 않는 기존의 모터와 발전기의 경우는 철심이 기기의 내 부를 거의 차지하고 있기 때문에, 2 차원 자장해석과 3 차원 자장해석의 결과 값이 거의 차이가 나지 않지만 공심형 구조를 갖는 초전도 발전기는 2 차원 해석에 의 한 자장분포와 3 차원 해석에 의한 자장분포의 차이가 무시할 수 없을 정도로 크게 되므로 설계오차를 줄이기 위해서 3차원 자장해석을 수행해야 한다[3].

이에 따라 자장해석을 위해 사용한 유한요소해석 프 로그램은 $\mathrm{ANSOFT}$ 사의 Maxwell이다. 총 6 극의 Racetrack 계자 코일은 각각 대칭성을 띄는 자장분포 를 가지므로 해석 시간을 줄이고 해석의 정확도를 증 가시키기 위해 1 극의 해석만으로도 전체 해석결과를 산출 할 수 있는 Master/Slave 경계조건을 사용하여 


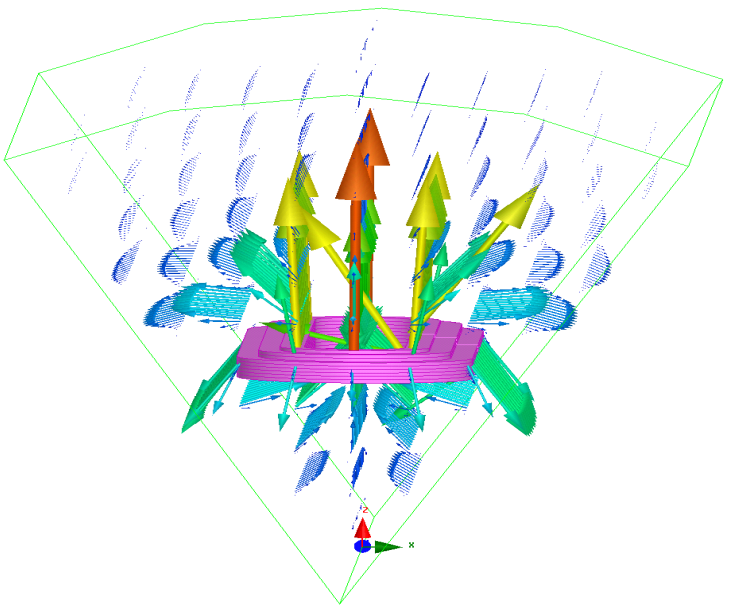

Fig. 5. Magnetic flux of the HTS field coil for 1 pole. 3

자장분포를 해석하였다[4].

초전도 계자코일에 $360 \mathrm{~A}$ 를 통전시켰을 경우 그림 5 에서 표시된 벡터의 크기와 방향으로 자장이 발생하 게 되며 그림 6 은 직선부와 곡선부에서의 3 차원 자장 분포이다. 초전도 계자코일의 직선부 자장분포만 얻을 수 있는 2 차원 해석과는 달리 3 차원 해석에서는 곡선 부의 자장분포까지 해석할 수 있기 때문에 2차원 해석 에서의 최대값보다 커지며 Racetrack형 계자코일의 곡선 부 안쪽에서 발생하고 그 크기는 최대 11.9 T가 된다. 곡선부에서의 최대자속밀도는 초전도 계자 코일 의 성능(self field 증가에 의한 임계전류감소)을 저하 시키는 요소가 되기 때문에 곡선부에서의 자장 분포 해석은 매우 중요하다.

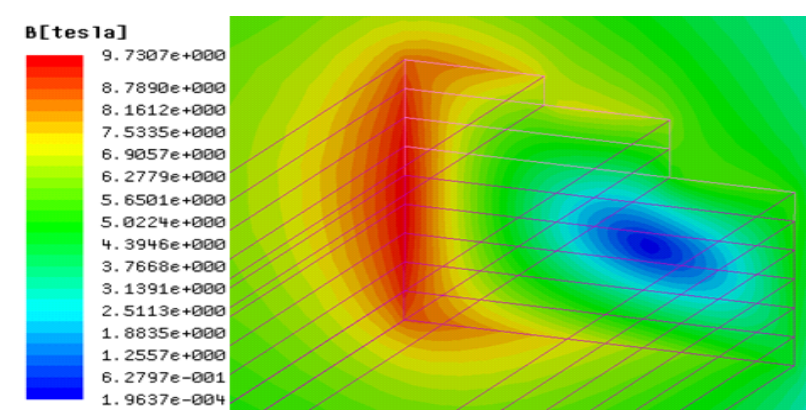

(a)

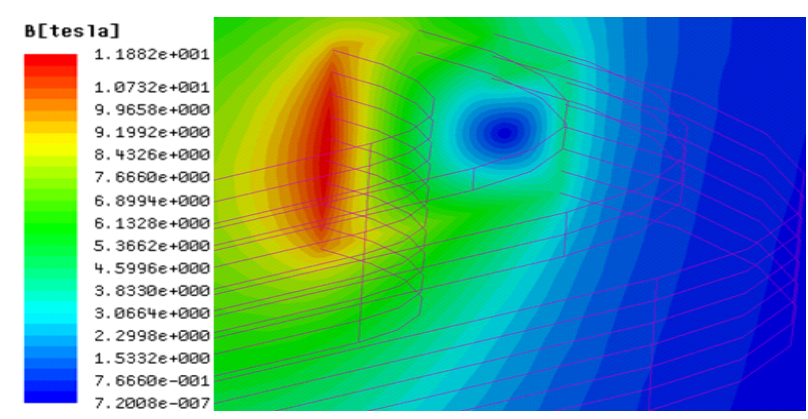

(b)

Fig. 6. 3D magnetic flux density distribution (a) at the linear part and (b) in the end sections.
Table 2. Maximum perpendicular and horizontal Magnetic flux density of the Field coil in each layer.

\begin{tabular}{|c|c|c|c|c|}
\hline \multirow{2}{*}{} & \multicolumn{2}{|c|}{ 직 선 부 } & \multicolumn{2}{c|}{ 곡 선 부 } \\
\cline { 2 - 5 } & $\mathrm{B} \perp[\mathrm{T}]$ & $\mathrm{B} / /[\mathrm{T}]$ & $\mathrm{B} \perp[\mathrm{T}]$ & $\mathrm{B} / /[\mathrm{T}]$ \\
\hline $\mathrm{SP} 1$ & 7.12 & 8.4 & 7.09 & 10.2 \\
\hline $\mathrm{SP} 2$ & 6.98 & 9.07 & 6.5 & 11 \\
\hline $\mathrm{SP} 3$ & 5.42 & 9.4 & 4.9 & 11.5 \\
\hline $\mathrm{SP} 4$ & 5.27 & 9.7 & 4.76 & 11.83 \\
\hline $\mathrm{SP} 5$ & 3.21 & 9.73 & 2.85 & 11.9 \\
\hline $\mathrm{SP} 6$ & 1.64 & 9.73 & 1.46 & 11.9 \\
\hline $\mathrm{SP} 7$ & 3.22 & 9.6 & 2.98 & 11.7 \\
\hline $\mathrm{SP} 8$ & 4.92 & 9.3 & 4.59 & 11.3 \\
\hline $\mathrm{SP} 9$ & 6.7 & 8.8 & 6.3 & 10.6 \\
\hline
\end{tabular}

표 2 는 곡선부의 자장분포까지 고려한 3차원 Racetrack형 계자코일의 층별 최대 수직 $(\mathrm{B} \perp)$, 수평 $(\mathrm{B} / /)$ 자장값을 나타낸 도표이며, 그림 7 은 그에 따 른 그래프이다.

이등방성을 갖는 테이프 형태의 고온초전도 선재에 통전 할 수 있는 임계전류 밀도 $\mathrm{Jc}$ 는 초전도 선재에 분포하는 자장의 방향에 따라 달라지는 특성을 보인 다. $2 \mathrm{G}$ 초전도 선재의 임계전류 밀도 $\mathrm{Jc}$ 는 수평자장 보다 수직 자장에 더 많은 영향을 받아 동일한 자장에 서 더 많은 감소를 보이는 특징을 갖고 있다. 코일의 임계전류 밀도 $\mathrm{Jc}$ 를 가장 크게 저하시키는 선재 면에 서의 수직방향자장은 상, 하부 코일로 갈수록 큰 값을 보이며 최대크기는 SP1 코일의 직선 부와 곡선 부에 서 각각 최대 $7.12 \mathrm{~T}$ 와 $7.09 \mathrm{~T}$ 이다. 따라서 동일한 특성의 $2 \mathrm{G}$ 선재를 사용할 경우 전체 계자코일의 임계 전류는 $\mathrm{SP} 1$ 코일의 최대 $\mathrm{B} \perp$ 에 의해 결정 되어 지므 로 계자코일에 통전할 수 있는 임계전류를 최적화하기 위해서는 $\mathrm{SP} 1$ 코일의 $\mathrm{B} \perp$ 을 최소화 할 수 있는 구조 적 설계가 이뤄 져야 할 것이다.

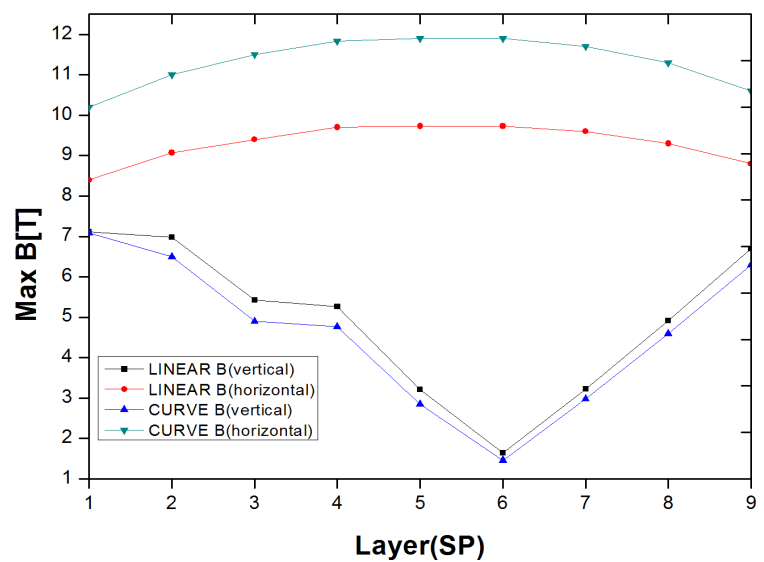

Fig. 7. Max perpendicular and horizontal magnetic flux density curve of the field coil in each layer. 
초전도 발전기는 공심형 구조로 인해 계자에서는 높 은 암페어-턴(Ampere-turns)을 필요로 한다. 따라서 철심으로 구성된 기존 기기의 계자 코일보다 훨씬 높 은 자장이 초전도 계자 코일에 작용하고 이에 따른 Lorentz force가 매우 커지게 된다[5]. 계자 코일에 작용하는 Lorentz force를 결정하는 수평자장은 코일 안쪽에서 큰 값을 보였고 그 크기는 직선 부와 곡선 부에서 각각 최대 $9.73 \mathrm{~T}$ 와 $11.9 \mathrm{~T}$ 이다. 이에 따른 한극의 계자코일이 받는 Lorentz force는 X방향이 $0.077 \mathrm{kN}, \quad \mathrm{Y}$ 방향으로 $0.012 \mathrm{kN}$, Z방향으로 - $2280 \mathrm{kN}$ 이며 전체 크기는 $2280 \mathrm{kN}$ 이다. 계자코일 에 작용하는 Lorentz force는 Z방향으로 작용하는 힘 에 의해 결정되어 진다.

\section{3. $10 \mathrm{MW}$ 급 고온초전도 풍력 발전기 계자 코일의 임계전류 산출}

초전도 선재의 임계전류 $\left(I_{C}\right)$ 를 산출하기 위하여 식 (1)을 사용하였다.

$$
V_{i}=V_{c}\left(\frac{I}{I_{C}(B, T)}\right)^{n(B, T)}[\mu \mathrm{V} / \mathrm{cm}]
$$

여기서 $V_{i}$ 는 코일 양단에 걸리는 전압이고, $V_{c}$ 는 $1 \mu \mathrm{V} / \mathrm{cm}$ 이고 I는 코일에 흐르는 전류이며, $I_{C}(B, T)$ 는 고온초전도 선재의 자장과 온도에 따른 임계전류를 나 타내고, $\mathrm{n}(\mathrm{B}, \mathrm{T})$ 은 자장과 온도에 따른 인덱스 값이다 [6]. 그림 8은 계자코일의 임계전류를 산출하기 위해 사용한 초전도 선재의 $I_{c}(\mathrm{~B}, \mathrm{~T})$ 특성곡선이며[7], 그림 9 는 운전전류 $\left(I_{O P}\right) 360 \mathrm{~A}$ 를 통전 할 경우 각 층에 발생되는 수직자장과 $30 \mathrm{~K}$ 의 운전온도를 기준으로 한 $10 \mathrm{MW}$ 급 고온초전도 풍력발전기 계자 코일의 임계 전류를 산출한 특성곡선이다.

각 층의 임계전류는 직선부에서 최소 $467 \mathrm{~A}$ 에서 최 대 $835 \mathrm{~A}$ 사이의 값이 계산 되었고, 곡선부에서 최소 $467 \mathrm{~A}$ 에서 최대 $879 \mathrm{~A}$ 사이의 값이 계산 되었다.

수직자장이 가장 큰 $\mathrm{SP} 1$ 의 임계전류는 $467 \mathrm{~A}$ 로 동일한 $2 \mathrm{G}$ 선재를 사용할 경우에 $\mathrm{SP} 1$ 의 임계전류를 기준으로 선재를 선정해야 함을 알 수 있다. 또한 선 재 사용의 효율을 높이고 계자코일의 제작비용을 줄이 기 위해 각 층의 임계전류에 따른 최적화된 선재를 정 하여야 할 필요가 있다.

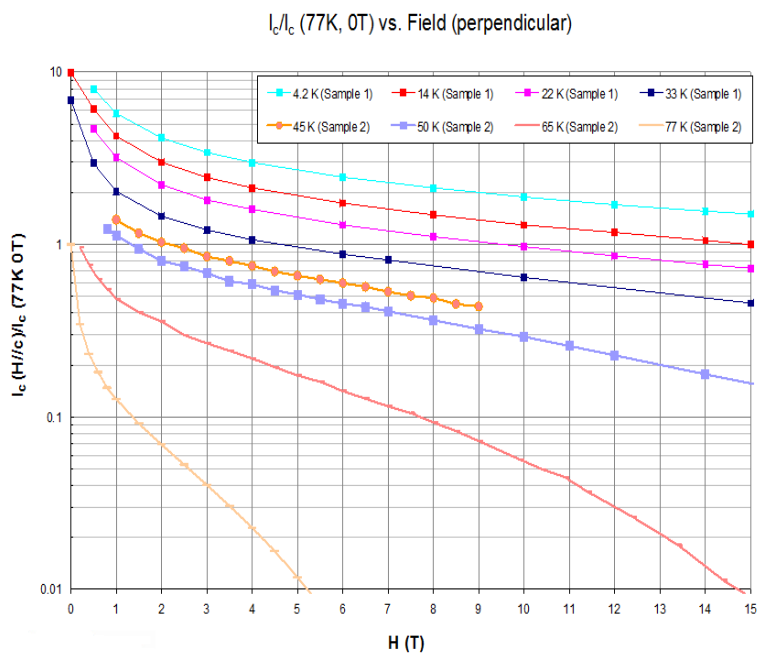

Fig. 8. The characteristic curve of the 2G HTS wire.

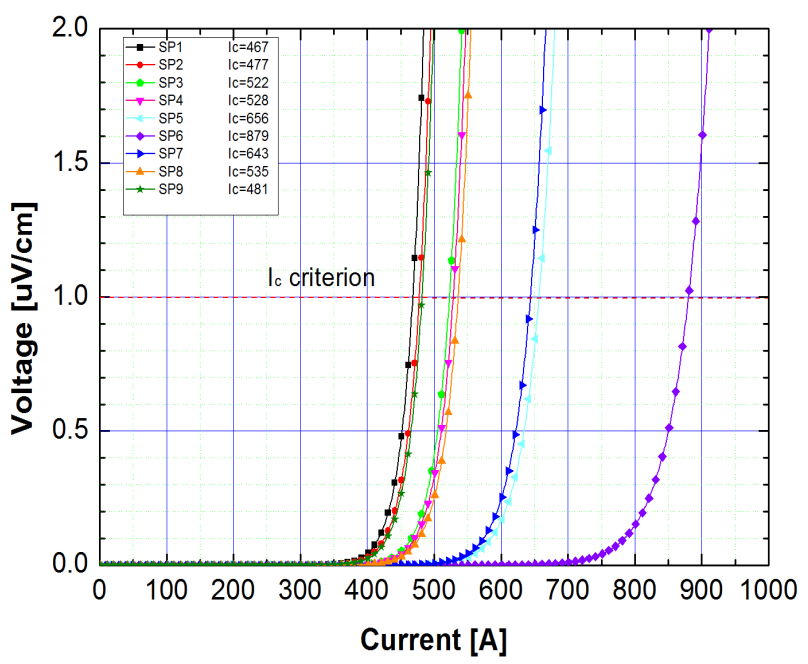

(a)

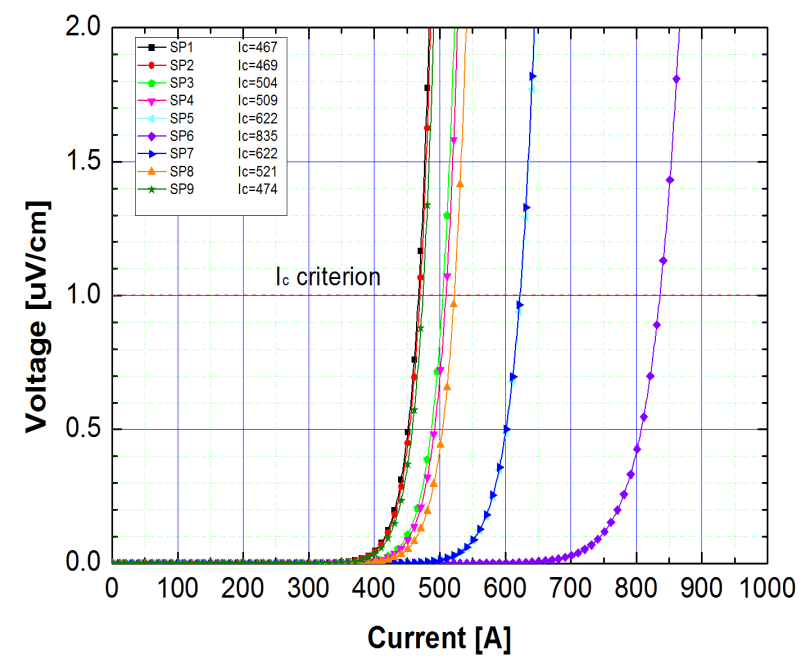

(b)

Fig. 9. Critical current curve of the field Coil (a) at the linear part and (b) in the end sections.

이를 위해 $I_{O P} / I_{C}$ 가 $70 \%$ 일경우의 $I_{C} 514 \mathrm{~A}$ 를 기 준으로 했을 경우 각 층의 임계전류와 비교하여 최적 화된 선재를 사용해야 한다. 특히 SP6은 운전전류보 다 약 1.7 배의 임계전류 값을 갖기 때문에 선재 사용 효율이 매우 떨어지게 된다.

\section{3. 결 론}

본 논문에서는 3차원 $\mathrm{FEM}$ 을 통하여 $10 \mathrm{MW}$ 급 초 전도 풍력발전기 계자코일의 정자장 분포를 해석하였 고 이에 따른 Lorentz force와 각 층의 임계전류를 산출하였다.

$\mathrm{HTS}$ 계자코일에 작용하는 자장분포를 성분 별로 해석한 결과 코일의 임계전류를 결정하는 수직자장은 상, 하부 코일로 갈수록 큰 값을 보이며 그 크기는 직 선 부와 곡선 부에서 각각 최대 $6.99 \mathrm{~T}$ 와 $6.84 \mathrm{~T}$ 이 다. 계자 코일에 작용하는 Lorentz force를 결정하는 수평자장은 코일 안쪽에서 큰 값을 보였고 그 크기는 직선 부와 곡선 부에서 각각 최대 $9.78 \mathrm{~T}$ 와 $11.9 \mathrm{~T}$ 
이다. 자장해석을 통해 산출한 최대 수직자장 값을 사 용하여 각 층마다 통전할 수 있는 임계전류 값을 산출 한 결과 $30 \mathrm{~K}$ 운전 온도에서 수직자장이 가장 큰 $\mathrm{SP} 1$ 의 임계전류는 $467 \mathrm{~A}$ 로 최적의 선재 선택과 계 자 정격 운전전류를 산정하는 데 있어 중요한 기준 값 으로 사용 할 수 있다.

추후의 연구를 통해 $30 \mathrm{~K}$ 이외의 운전온도에서의 임계전류를 산출하여 $10 \mathrm{MW}$ 급 고온초전도 풍력발전 기 설계를 위한 중요한 파라미터로 사용 될 수 있음을 알 수 있었고 Lorentz force를 통한 초전도 계자코일 의 응력 분포 해석을 수행하여 초전도 선재의 인장강 도에 따른 최적의 선재 조건 선택과 초전도 계자코일 에 작용하는 전자기적 응력을 최소화하는 구조적 설계 가 수행 되어야 함을 알 수 있었다.

\section{감사의 글}

본 연구는 지식경제부 한국에너지기술평가원의 신 재생에너지기술개발사업과 국제공동연구개발사업의 연구비 지원에 의한 것입니다. (20118520020020), (20113020020020)

\section{참 고 문 헌}

〔1] 김호민, “해상풍력용 발전기 기술 및 전망”, 초전 도와 저온공학, 13권 1호, pp. 13 21, 2011

[2] 김지형, 김호민, “고온초전도 풍력발전기 기술”, 한국전기전자재료학회 합동 춘계학술대회 논문지, pp. 26, 2012.

[3] 백승규, 손명환, 이언용, 권운식, 조영식, 권영길, “고온초전도 동기모터의 3차원 자장 분포 영향”, 대한전기학회 하계학술대회 논문집, $\mathrm{pp}$. 768 770, 2003.

[4] Maxwell 3D Technical Notes, Version 14.0, ANSOFT, 2011.
〔5] 백승규, 권영길, 이언용, 이재득, 김영춘, 문태선, 박희주, 권운식, “ $1 \mathrm{MW}$ 급 고온초전도 동기기의 전자기적 특성 해석”, 한국초전도·저온공학회 논 문지, 9권 3호, pp. 32 36, 2007년 9월.

[6] 이재득, 이상호, 김호민, 이언용, 백승규, 권영길, 홍정표, 박민원, 유인근, “고온초전도 Homopolar 전동기용 계자코일의 설계 및 특성평가”, 대한전기 학회 하계학술대회 논문집, pp. 784 785, 2008 년 7월.

[7] "Performance data of 2G HTS wires.", 2008 Applied Superconductivity Conference, USA, Aug., 2008

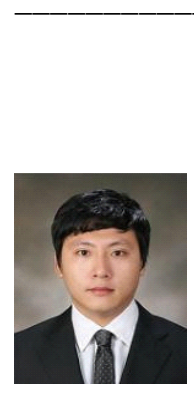

$$
\text { 저 자 소 개 }
$$

김지형 (金志炣)

1984년 07월 04일생, 2010년 제주대 공대 전기공학과 졸업, 현재 제주대 대 학원 전기공학과 석사과정.

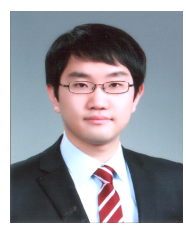

박사일 (朴士日)

1986년 01월 06일생, 2011년 제주대 공대 전기공학과 졸업, 현재 제주대 대 학원 풍력특성화협동과정 석사과정.

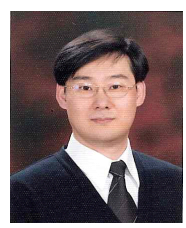

김호민 (金鎬民)

1970년 8월 23일생, 2002년 연세대학교 전기전자공학과 졸업 (공학박사), 2002 년 2004년 M.I.T. Francis Bitter Magnget Lab. Post-Doctoral Research Associate, 2004년 2006년 $\mathrm{LG}$ 산전(주) 전력연구소 선임연구원, 2006년 2011년 한국전기연구원 초전도 연구센터 선임연구원, 2011 현재 제주대 학교 전기공학과 조교수. 